\title{
A NOTE ON FREE PRODUCTS
}

\author{
DON HADWIN AND XIUJUAN MA
}

\begin{abstract}
We answer two questions raised by I. M. Singer concerning free products. We prove that in a free product of separable unital $\mathrm{C}^{*}$-algebras, states on each algebra can be simultaneously extended to a pure state on the free product. We also show that the second dual of the free product of unital $\mathrm{C}^{*}$-algebras is the von Neumann algebra free product of their second duals. We give a proof that the extreme points of the set of tracial states of a $\mathrm{C}^{*}$-algebra is the set of factor tracial states.
\end{abstract}

Mathematics subject classification (2000): 46L09, 46L30, 46L05.

Key words and phrases: Free product, $\mathrm{C}^{*}$-algebra, state, pure state.

\section{REFERENCES}

[1] Arveson, William, An invitation to $C^{*}$-algebras, Graduate Texts in Mathematics, No. 39, SpringerVerlag, New York-Heidelberg, 1976.

[2] Ching, WaI-MeE, Free products of von Neumann algebras, Trans. Amer. Math. Soc. 178 (1973) 147-163.

[3] HADwin, DON, A noncommutative moment problem, Proc. Amer. Math. Soc. 129 (2001), no. 6, $1785-1791$.

[4] Hadwin, Don; KaOnga, Llolsten; Mathes, Ben, Noncommutative continuous functions, J. Korean Math. Soc. 40 (2003), no. 5, 789-830.

[5] KADISON, RichaRd V.; Ringrose, JoHn R., Fundamentals of the theory of operator algebras, Vol. I, Elementary theory, Graduate Studies in Mathematics, 15, American Mathematical Society, Providence, RI, 1997.

[6] Kadison, Richard V.; Ringrose, John R., Fundamentals of the theory of operator algebras. Vol. II. Advanced theory, Graduate Studies in Mathematics, 16. American Mathematical Society, Providence, RI, 1997.

[7] Mac Lane, SAunders, Categories for the working mathematician, Graduate Texts in Mathematics, 5, Springer-Verlag, New York, 1998. 